\title{
16 Foresight and science, technology and innovation indicators
}

\author{
Dirk Meissner and Alexander Sokolov ${ }^{1}$
}

\section{INTRODUCTION}

Technology foresight as one of the key areas of forward-looking activities over the last two decades has become a tool with a significant influence on science, technology and innovation (STI) policies in many countries worldwide, with a much longer tradition in Japan and a few other countries. Since the early 1990s foresight has been evolving from an instrument to assess future prospects of individual research areas to an integral part of STI policy formulation and implementation. Luke Georghiou singles out five generations of foresight (Georghiou et al. 2008: 15-16) that vary from mainly forecasting that refers to the internal dynamics of technology to a wide mix of activities aimed at either structures of actors within the STI system or the STI dimensions of the broader social or economic context.

Foresight can affect the innovation performance of a country through different channels. In the present globalization context in the industrialized nations it is accepted that an explicit and coherent STI policy is essential for economic and social development. Foresight studies affect STI policy strategy decisions by supporting priority setting. They create, in addition, crucial networks and interactions between participants in the national system of innovation and contribute to the acceptance of new developments and to the consideration of all of the technological potentials (Martin 1995).

Since foresight, and STI indicators, are both aimed at informing and improving policy making, they naturally have much in common, are interdependent and complement each other.

The interrelations between foresight and STI indicators are many. On the one hand, indicators are extensively used in foresight to provide data on STI trends, thus stimulating experts' creative thinking and solidifying their judgements. On the other hand, foresight exercises contribute to highlighting new areas of concern for STI policy that can and should be addressed by statistical measurement and emerging research areas with a great innovation potential that needs more detailed statistical analysis. 
Between these two extremes, there are many other fields where the two areas are closely related.

Another topic of increasing interest is the search for suitable practically proven indicators available for measuring and assessing foresight studies as such, for example in terms of management but also with respect to their eventual impact in either a direct or indirect way on the national innovation system (NIS) and on long-term economic performance. Hence there is an urgent need to develop and apply a coherent and consistent set of indicators suitable for monitoring the effectiveness and efficiency of foresight studies from a process perspective and that can contribute to measuring their impact.

This chapter introduces three major dimensions of interrelations between foresight and STI indicators: (1) use of indicators in the course of foresight studies; (2) building particular STI indicators to monitor and measure foresight activities; and (3) the contribution of foresight to complementing existing indicators and developing new ones.

\section{FORESIGHT AND ITS MANIFESTATIONS}

According to Ben Martin's classical definition, foresight is a 'process involved in systematically attempting to look into the longer-term future of science, technology, the economy and society with the aim of identifying the areas of strategic research and the emerging generic technologies likely to yield the greatest economic and social benefits' (Martin 1995: 142). Currently, foresight is used as a set of instruments to support and improve decision making.

Usually foresight studies also contribute to knowledge creation, absorption and diffusion. They see the technological regime in a broad sense, for example describing and anticipating varying scenarios surrounding actual technological trends (Malanowski and Zweck 2007: 1806). Hence it can be assumed, if not concluded, that foresight studies have a significant impact on the design of national innovation systems but also on national innovation performance in a long-term perspective.

Foresight envisages an open and interdisciplinary discussion and communication culture, facilitating the exchange between actors from policy administration, industry, science and society, fostering the interaction between them as well as supporting networking and the implementation of results. In principle these studies follow systemic, integrative approaches with different instruments and methods, and aim at matching diverging interests and achieving consensus between all parties, thus requiring commitment of key stakeholders. More general groupings of foresight 
exercises address different aims, territorial needs, outputs and the results attained (Gavigan et al. 2001; Molas-Gallart et al. 2002; Keenan 2003; Cuhls 2003; Meissner 2013a).

Foresight does not aim to predict a predetermined future but through the involvement of players and decisions taken 'today', it allows participants in foresight studies to actively shape the future, but to a modest degree only. Current foresight exercises quite often involve a wide range of stakeholders, thereby opening the minds of participants to new possibilities for the future (Cachia et al. 2007; Sokolov 2013). They constitute powerful assistants in planning and managing uncertainty levels. Foresight offers possibilities to identify and take advantage of opportunities; to investigate and understand the nature of risks inherent in the innovation process; and to develop reaction to mitigate problems once they start to unfold (Santo et al. 2006).

Foresight studies can take many different shapes. Lempert et al. (2003) suggest grouping such studies into the following categories: top-down versus bottom-up; explorative versus normative; quantitative versus qualitative; and expert-based versus assumption-based. Another approach by Popper proposes the 'foresight diamond' (see below), which builds on the ability to gather and process information, for example evidence, expertise, interaction and creativity (Popper 2011). Other approaches towards grouping foresight studies are centred around particular fields of the foresight study (Tran and Daim 2008; Godwin and Wright 2010; Höjer and Mattsson 2000; Bishop et al. 2007; Bradfield et al. 2005; van Notten et al. 2003; Ringland 1998; Voros 2006) or on the use of methodologies (Popper 2008; Keenan and Popper 2007).

Traditionally the application of indicators to predict the future from modelling (often with the use of time series) is based on the assumption that the general system will remain unchanged and therefore further development will be of a deterministic nature. This is valid for well-defined systems reflecting physical laws, but is misleading when it is related to innovation. Since innovation is a non-linear process based both on creativity and on innovative use of existing goods/services, foresight activities are more productive when they are not just aimed at predicting indicators on the basis of existing models (trends extrapolation and other such methods) but try to articulate new problems to be resolved, to reveal new trends and to construct relevant categories to be addressed by policy makers.

Given this context, the key questions for this chapter are as follows: 'How can foresight use existing indicators to become more efficient and more effective?'; 'What can foresight contribute to making the system of STI indicators more relevant to existing and emerging policy concerns?' and 'How can foresight and STI indicators, together, provide valuable background for decision makers?' 


\section{THE USE OF INDICATORS IN THE FORESIGHT PROCESS}

Foresight has been increasingly considered as a systematic process. It consists of five interconnected and complementary phases (Miles 2002; Georghiou et al. 2008: 45): pre-foresight; recruitment; generation; action; and renewal. At each of these phases STI indicators can be used as a valuable source of information.

At the pre-foresight stage, the overall goals of the project are set, including rationale, thematic domain, territorial scale, time horizon and expected outcomes. At this stage analysis of STI indicators helps to more precisely identify major issues to be addressed by the study and create a background for further actions.

During the succeeding recruitment stage, bibliometric and patent analysis is used for the identification of key experts and institutions to be involved in the exercise. For this purpose, analysis of the dynamics of publications and mapping the development of and interconnection between research areas as well as assessments of new (interdisciplinary) research areas based on STI indicators are of high relevance for foresight studies. Participation of the best specialists (highly cited researchers, inventors, innovators etc.) is a key success factor for any foresight project.

Following the pre-foresight and recruitment stages, the generation phase covers a number of activities aimed at extracting expert knowledge and building a shared vision by anticipating possible futures and selecting desirable ones. Thus detailed description of research fronts is the core of this phase. Involvement of experts at this stage allows the early identification of issues, the elaboration of scenarios and the discussion and interpretation of results (Wehnert and Jörß 2009). This phase is related to analysis of existing codified knowledge (e.g. expressed in the form of STI indicators), extraction and codifying of tacit knowledge, and generating on this base new knowledge related to the future.

In the action phase the new knowledge generated through foresight activities is used for prioritization and policy making in the field of STI. Revising policy instruments requires developing new instruments to measure their efficiency, which leads to a demand for new STI indicators.

The renewal phase is focused on monitoring and evaluation of the foresight results, although sometimes this evaluation is not an easy exercise and requires specific approaches as well as a system of relevant indicators (see the discussion below).

Foresight methodology includes many qualitative, quantitative and semi-quantitative methods. Traditionally, foresight was mainly built on qualitative methods based on expert judgements, but during the last 


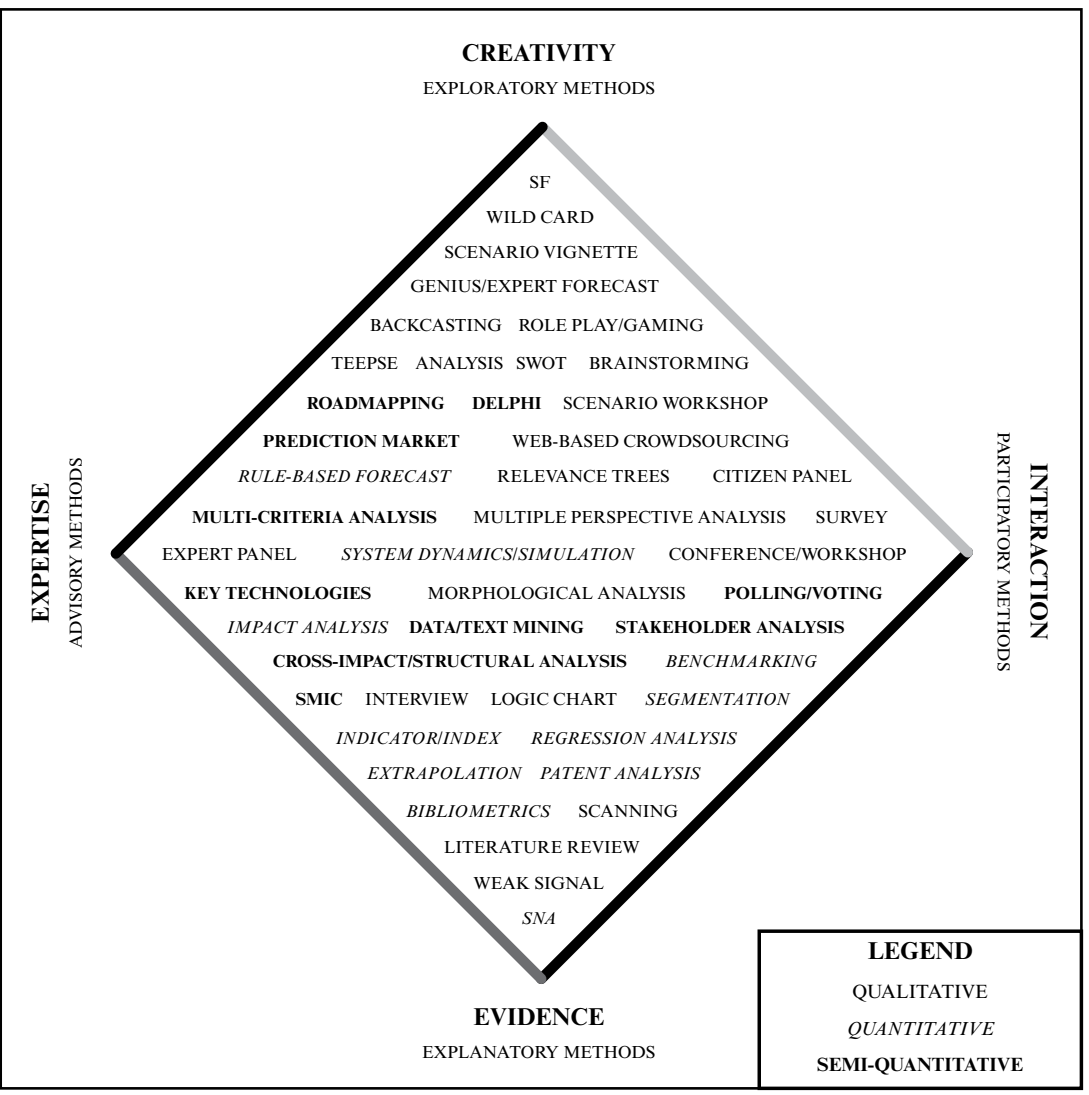

Source: Popper (2011).

\section{Figure 16.1 The foresight diamond}

decade a clear trend towards inclusion of evidence-based methods can be observed. The foresight diamond (Figure 16.1) includes such methods as modelling, trend extrapolation, patent analysis, analysis of statistical indicators as well as a number of methods that include quantitative analysis as an integral part. Two examples are the Delphi method and roadmapping.

Indicators for measuring and monitoring foresight studies comprise a fairly new field of science and are also rather new when it comes to practical application. Such indicators need to go far beyond the established evaluation and impact measurement of STI policy measures. Moreover, they need to take into consideration the many different forms in which foresight studies appear. Also foresight usually has a very broad target 
audience and involves a large number of stakeholders with their own expectations on the implementation and use of the results. Hence the impact of foresight studies is in theory assumed to be very strong once all stakeholders support both the actual process and the result implementation. However, practical experience shows that the implementation of the results achieved is far more difficult and challenging than the process itself, for example running the study.

A completely different picture arises when it comes to indicators used in the course of foresight studies. Such indicators are designed for various purposes, for example to describe technology development paths, to determine technology development priorities, to detect societal needs and requirements, among others. Thus foresight studies are used as an instrument to prepare countries for meeting future challenges such as contributing to enhanced industry-science relationships, the cooperation and coordination of administrative and political institutions and actors, and providing a useful tool for research strategy development by many different actors, for example research institutions, universities and public funding agencies. In addition, foresight studies are increasingly used as radar by industry to identify societal feelings and development trends (Vishnevskiy et al. 2013).

Furthermore, indicators arising from foresight studies need to take special characteristics into account, for example with respect to the longterm focus and the time horizon varying according to the topic discussed (in most cases between 10 and 30 years). Also such studies apply an open and interdisciplinary discussion and communication culture, facilitating the exchange between actors from policy administration, industry, science and society, fostering the interaction between representatives from science, technology, economy, culture and social as well as supporting networking to strengthen the implementation of results. In principle these studies follow systemic, integrative approaches with different instruments and methods, and aim to match diverging interests and achieve consensus between key stakeholders.

Foresight exercises usually have long time horizons (10 to 50 years or more) and take a broad view of environment, organization and strategies, commonly resulting in scenarios that in turn usually contribute to stakeholder learning, stimulate imagination and enhance aspiration (Bezold 2010). The ultimate goal of national foresight projects is to coordinate research and innovation agendas across public and private organizations, industrial and service sectors, and academic disciplines by developing new alliances between the producers and the consumers of knowledge. These projects take into account and make visible the processes by which research agendas and priorities are established, the degree and nature of 
autonomy in the practices of scientists and engineers, the relations of academic disciplines to one another and to industrial knowledge, and the ends to which S\&T are directed (Rappert 1999).

\section{INDICATORS FOR MONITORING AND EVALUATION OF FORESIGHT}

\section{Features of Foresight Studies - Implications for the Evaluation of Foresight}

Foresight studies are not at all, or only in very few cases, aligned to the strategic agenda of their initiator. Moreover, especially weak signals currently gaining importance in foresight practice are left aside from the integration into the organization's strategies (Battistella and De Toni 2011).

Grim (2009) introduced a Foresight Maturity Model (FMM) including six major elements that characterize the essentials of foresight studies: leadership, framing, scanning, forecasting, visioning and planning. The framework aims to provide organizations with a tool to assess their current position in the future orientation of their competences and practices. The FMM aims to evaluate and monitor the competences and capabilities of organizations not only to design and conduct foresight studies but also to prepare the organizations themselves for future requirements and challenges (Grim 2009). Hence the leadership indicator aims to convert the foresight into practical action on an ongoing basis, the framing dimension focuses on the degree to which the right issues are identified and solved, and scanning refers to the immediate environment of the organization. The forecasting competences are the central element of the model, visioning is meant to develop future visions and finally planning expresses the ability of organizations to develop tools that support the implementation of the generated vision. With the help of the FMM, the maturity of the organization in foresight terms can be determined at five levels: ad $h o c$, aware, capable, mature, world-class. Another increasingly common feature of foresight studies is the inclusion of future application potentials expressed as market potential (although it is often difficult to determine).

The acceleration of innovation in most STI fields has led to the phenomenon that new product groups are entering markets for the first time even before their physical fundamentals are fully understood (Malanowski and Zweck 2007). Thus the identification of application fields and potential markets for technologies is characterized by higher uncertainty than ever as the applications of technologies might change in the course of their maturity. For evaluating and monitoring foresight studies, indicators are needed that measure the long-term accuracy of the identified application 
and market fields, for example the percentage of change in applications. Also indicators for evaluation need to reflect the changes in technology application that might occur over time due to societal change associated with the embedding of the technology in the society.

Furthermore, the technology is characterized by inherent uncertainty when it comes to actual large-scale industrial application. Technological attractiveness as determined by foresight studies is by no means a guarantee that the technology is applied in the identified fields, but foresight also needs to consider the particular conditions that must be met in order to ease the feasibility of technology application (related industries, infrastructures, skilled labour etc.) (TFAMWG 2004). Quantitative methods are increasingly used for building integrated STI indicators that offer numerous opportunities for foresight (Haegeman et al. 2012). The most popular quantitative methods use bibliometric and patent indicators and Internet-based tools, allowing for the integration of data. Bibliometric studies have been widely used as a valuable source of data for foresight, allowing the identification of emerging research fields that can offer disruptive technologies in five to ten years ahead. Innovation forecasting models commonly use frequency analysis of keywords in scientific publications. Incremental and radical innovations can be distinguished through the analysis of emerging clusters with respect to citations and keywords for a particular technology field. Another area for using bibliometric and patent data is to distinguish between groups of technologies and vice versa for cross-impact analysis to identify relationships between technologies.

Foresight studies have both a direct and an indirect impact. Direct impacts refer to information about the extent and the features of future situations, the future environment and/or possible future partners or competitors, for the benefit of organizational processes such as decision making, strategy design, formulating new perspectives on growth, building new alliances and allocation of management capacity for the stakeholders. Indirect impacts express the culture of the stakeholders and the implications of that culture for the future. Foresight studies also enable and incentivize stakeholders to think about what is important in the present, about biases in current reflections and other perspectives that are currently not considered (van der Steen et al. 2011).

One major outcome of national foresight studies used to be as a supporting tool for priority setting in public national R\&D spending. However, there remains a great debate about the appropriateness of foresight results for priority setting, especially those that express a predictable but still uncertain future. Thus in the design of foresight studies special attention needs to be given to the role of national policy in coordinating organizations, the participants involved in the development of future scenarios, 
and the extent to which these scenarios can contribute to setting public research priorities (Rappert 1999).

The need for ex ante assessment of foresight exercises stems from the requirement to check all possible impact dimensions and to evaluate the likelihood of their realization and their strengths, while ex post impact assessments are able to evaluate the efficacy and the efficiency of the foresight projects by measuring and monitoring their performance (i.e. datagathering and reporting strategies) and practices to review the foresight (Blind 2004).

New developments in S\&T detected by foresight studies often challenge the existing research agendas, or call for the redirection of research and technology roadmaps and agendas (Meissner et al. 2013). Changes and dynamics in S\&T can be identified and traced by different indicators. These indicators must allow for the comparison between S\&T fields, countries, organizations and over time. Currently the most common indicators for such comparison are publications in scientific journals and patents (Moed et al. 2004). The former indicators help to visualize the ongoing trends in basic research, whereas publication and patent indicators cover the change in applied R\&D.

\section{Evaluation of Foresight Indicators}

Georghiou and Keenan (2006) distinguish three classes of evaluation criteria. First, they discuss the efficiency of implementation, second, the impact and effectiveness, and third, the appropriateness of the foresight exercise. The efficiency of implementation concentrates mainly on the procedural perspective, for example organization and management. Typical indicators developed during evaluation are the background and the competences of the people involved, the degree of support to expert panels, the link to decision makers but also the appropriateness and efficiency of methods used. Impact and effectiveness indicators reflect the immediate outputs and outcomes. According to Georghiou and Keenan, outputs measure only activity; for example they count quantitative data such as numbers of participants in meetings or surveys, reports disseminated, meetings held, website hits and so on, but there is no real assessment of the short- and long-term impact of these. Moreover, these indictors have an inherent potential to lead to misinterpretation and misunderstanding as they do not express novelty, size, significance and sustainability. The appropriateness indicators reflect a scenario-type style of evaluation centred around the 'what if ...' questions, for example highlighting alternative scenarios (Georghiou and Keenan 2006).

The evaluation of foresight exercises also needs to take into account the 
dynamics of the project, for example be conducted in real time or immediately after to ensure that the findings are not distorted by hindsight or obscured by loss of data (Georghiou and Keenan 2006).

According to Saritas and Oner (2004), there is a lack of translating future requirements into $\mathrm{R} \& \mathrm{D}$ projects and initiatives. In the course of most foresight exercises topic statements are formulated and assessed using different instruments that place more emphasis on action rather than on theoretical understanding of the underlying science. Hence evaluation indicators need to be developed that take account of this gap.

\section{Basic Definitions and Characteristics of Indicators}

The structure and composition of foresight studies raises another challenge. Two types of foresight studies have to be considered: (1) with a clear focus on selected themes and a narrow scope consisting of one project; and (2) with a broader scope that includes several projects. Indicators used for monitoring or evaluating foresight studies thus need to consider the interdependencies of different projects that make up a broad foresight study. Therefore indicators need to consider not only the single projects but also the whole project portfolio (Meissner 2013b). Thus indicators to measure and monitor foresight studies can be grouped into three major areas:

- measurement and monitoring objective;

- time horizon; and

- resource orientation.

\section{Measurement and monitoring objective}

In principle, three major perspectives are measured and monitored:

- monitoring and steering of the foresight study (process perspective);

- measuring the impact of the foresight study - long-term impact measurement, multiple impacts on diverging surroundings; and

- near-time evaluation of foresight studies.

Process indicators During foresight studies bibliometric indicators are often used to determine the importance of selected trends in different facets or to assess the national or institutional strengths and weaknesses.

Evaluation perspective Typically foresight studies are initiated, issued and financed by public bodies and funds. Thus in most countries evaluation is an integral part of foresight, and in the first instance it aims at testing the effectiveness and efficiency of the study. To some extent evalu- 
ation indicators also reflect the (mainly short-term) impact achieved with the foresight study. Evaluation of foresight studies (as projects) refers to two dimensions:

- Effectiveness - 'doing the right things' - is measured by long-term indicators and addresses the question of whether the goals and ambitions of the foresight study were achieved once the study is complete. That includes building an inventory of all activities taking place, matching these with the original scheduled activities and determining whether the activities have contributed to the goals. Such analysis will give the evaluators of the study reliable information.

- Efficiency - 'doing the things right' - is measured through assessment of the value achieved from the input of resources, for example the ratio of input and output indicators. Input indicators need to mirror not only the actual financial resources spent but also take into account the non-financial investments, especially the time and know-how of experts other than the project team used for conducting the study. Usually external experts are not reimbursed for most of the working time they provide to the foresight study team; hence quantifying these efforts in a reliable and solid way is critical. The problem in determining these values lies in the fact that no direct cost can be attributed to the study, nor is there an existing market mechanism which would provide a market price.

Impact perspective Impact indicators are designed to measure the impact caused by the foresight study. Such impacts can be of a direct as well as an indirect nature. Direct impacts refer to actions taken as a consequence of the foresight study and related results. For example, such impacts are redesigned or restructured research portfolios and adjusted and adapted research funding programmes. Indirect impacts refer more to qualitative impacts that arose from the study. Examples are effects that arise from networking and also from communication and media activities.

\section{Time horizon}

A second dimension for grouping indicators relates to the time horizon on which the indicators focus. These are leading, lagging and learning (accordingly ex ante, ex post and monitoring indicators) and, finally, resource-oriented indicators, for example input, output and process indicators.

Leading (ex ante) Leading indicators summarize expected framework conditions and match them with the potential impacts of a foresight study. 
Leading indicators follow the exploration of a current trend derived from past experiences or from qualitative assessment of experts. A combination of both methods (trend exploration and expert assessments) is a possible methodology. Hence ex ante indicators look towards the future and predict potential developments in different ways. Leading indicators are thus considered to be indicative but not necessarily accurate. They require regular updates of the information base on which the indicator is built. Changes of the leading indicators in the course of time are interpreted as upcoming changes in the real situation. Commonly, leading indicators are used in economics and business. There are many examples of leading indicators, one of which is The Conference Board Leading Economic Index ${ }^{\circledR}$ (LEI) for the USA. It uses ten data series to reduce volatility and is produced for the USA and other countries (www.conference-board.org/ data/bcicountry.cfm?cid=1).

Lagging (ex post) Lagging indicators oriented towards describing the past are often used to assess whether the foresight study was done efficiently, for example whether the things were done right. With a reasonable time lag the effectiveness of foresight studies can be evaluated, although caution is required here since foresight studies on average have a 10-20-year time horizon. First, effectiveness cannot be reliably assessed before the study has reached its full impact. Second, after a long period of time, the real contribution of a foresight study towards any impact generated is difficult to evaluate since, in the meantime, many factors may influence trends and developments. Despite these limitations, ex post evaluations of foresight offer a significant learning potential to draw from the experiences gained in studies carried out and already completed.

Learning (monitoring) The main function of these indicators is to provide near-time (real-time) information about the ongoing project (foresight study), thus providing an information base for project management and for leaders to react in near time. Besides the information function for immediate reaction, these indicators provide a valuable information source for learning in the sense of continuous improvement and further development, and adjustment of methodologies and processes.

Sometimes learning and monitoring indicators are also referred to as near-time, interim or controlling indicators.

\section{Resource orientation}

Evaluation and measurement studies always take into account the resources and processes that eventually lead to certain results. 
Input Measuring the input into foresight studies is a precondition for building and interpreting many related performance and monitoring indicators, but also for enabling benchmarking with other foresight studies. It has become practice in operational management to compare various foresight studies for different purposes. Input indicators include financial resources invested, but there is also a qualitative dimension in terms of the composition of human resources and their experience.

Output The output of a foresight study can take many different forms. Since results of foresight studies are not tradable goods, their value is difficult to determine in quantitative ways. The difficulties continue to grow with the long-term orientation of the outputs, for example regardless of which output is considered, the common feature is that issues and matters with a long time perspective are contained and explored in these documents. Typical outputs of foresight studies are scenarios, technology roadmaps, forecasts, analysis of trends and drivers, research and other priorities, policy recommendations and lists of key technologies. It is not advisable to gather the number of outputs, but rather the quality and newness of the content of the output. Quality is of relevance but it is difficult to measure in quantitative terms.

Process Process indicators are closely related to monitoring indicators. However, they are useful for ex post evaluation of the foresight study and especially for determining its efficiency. Process indicators combine major quantitative as well as qualitative indicators.

Table 16.1 shows that different indicator types are, to a varying extent, suitable for measuring different objects.

Effectiveness and efficiency of foresight studies are often assessed by the

Table 16.1 Suitability of indicators to measure different objectives

\begin{tabular}{llccc}
\hline & & \multicolumn{3}{c}{ Measurement perspective } \\
\cline { 3 - 5 } & & Process & Evaluation & Impact \\
\hline Indicator & Leading (ex ante) & $\downarrow$ & $\rightarrow$ & $\uparrow$ \\
type & Lagging (ex post) & $\rightarrow$ & $\uparrow$ & $\uparrow$ \\
& Learning (monitoring) & $\rightarrow$ & $\uparrow$ & $\rightarrow$ \\
& Input & $\downarrow$ & $\uparrow$ & $\rightarrow$ \\
& Output & $\downarrow$ & $\uparrow$ & $\uparrow$ \\
& Process & $\mathrm{n} / \mathrm{a}$ & $\uparrow$ & $\rightarrow$ \\
\hline
\end{tabular}

Note: $\quad \uparrow$ Fully suitable; $\rightarrow$ partially suitable; $\downarrow$ not suitable. 
estimation of impacts such as Delphi participation rate $;{ }^{2}$ thematic panels' feedback, accomplishment of the formally set goal in terms of specifying research areas. Data are usually collected via (empirical) evaluations and international comparisons. These are especially reviews of project management, personal and formal information obtained from client and stakeholders, as well as comparisons with key indicators of projects in other regions and countries.

The quality of foresight studies can be measured using additional constructed indicators such as survey participation rate, share of rejected participations, time needed for completion of the foresight study compared with time scheduled, resources needed for completion of the foresight study compared with resources scheduled (person days/person months) as well as resources needed for completion of the foresight study compared with resources scheduled (financial budget).

To monitor and evaluate ongoing foresight projects, typical indicators used are the accuracy of keeping milestones and deadlines for outputs, the share of workshop participants not appearing and the on-time completion of different projects (see Table 16.2).

While the individual indicators have some specific characteristics, developing and building a set of indicators for different purposes raises additional challenges. Despite the original purpose of indicator selection and development, a few underlying basic principles need to be taken into account. Indicators comprising a measurement or evaluation system need to be mutually exclusive but collectively exhaustive.

\section{Impact Dimensions of Foresight Studies}

Foresight studies have various impacts in different time horizons (see Table 16.3). The most significant impacts are usually considered to be of long term rather than showing immediate effects (Meissner 2013a). However, caution is recommended when it comes to measuring their real contribution to a given impact in the long term. This is mainly due to the fact that in the course of time the framework conditions are likely to change. Thus it is hardly possible to assess the total contribution of foresight studies and their respective results to the changed situation.

In particular, comprehensive foresight studies produce results that concern different ranges of the society and are relevant for policy development in a broad social context. However, it is appropriate to note that the emphasis on policy influence is likely to move the foresight study results in a politically correct direction. Such behaviour has been observed especially for those countries that conducted foresight studies for the first time. With studies focused on certain ranges, the effects are likewise only meas- 
Table 16.2 Criteria for assessing effectiveness, efficiency and quality of foresight studies

\begin{tabular}{|c|c|c|}
\hline Effectiveness & Efficiency & Quality indicators \\
\hline $\begin{array}{l}\text { Project } \\
\text { management } \\
\text { procedures }\end{array}$ & $\begin{array}{l}\text { Project management and } \\
\text { monitoring, followed up by } \\
\text { review }\end{array}$ & $\begin{array}{l}\text { Participation rate } \\
\text { surveys }\end{array}$ \\
\hline $\begin{array}{l}\text { (Empirical) } \\
\text { evaluation }\end{array}$ & $\begin{array}{l}\text { Personal and formal } \\
\text { information obtained from } \\
\text { client and stakeholders }\end{array}$ & $\begin{array}{l}\text { Share of rejected } \\
\text { participation }\end{array}$ \\
\hline $\begin{array}{c}\text { International } \\
\text { evaluation }\end{array}$ & $\begin{array}{l}\text { Assessment of change in } \\
\text { basic research culture, without } \\
\text { indicators }\end{array}$ & $\begin{array}{l}\text { Time needed for } \\
\text { completion of foresight } \\
\text { study versus time } \\
\text { scheduled }\end{array}$ \\
\hline $\begin{array}{l}\text { Indicators of } \\
\text { impact and } \\
\text { the Delphi } \\
\text { participation } \\
\text { rate }\end{array}$ & $\begin{array}{l}\text { Comparing with cost of } \\
\text { similar projects in other } \\
\text { countries }\end{array}$ & $\begin{array}{l}\text { Resources needed for } \\
\text { completion of foresight } \\
\text { study versus resources } \\
\text { scheduled (person days/ } \\
\text { person months) }\end{array}$ \\
\hline $\begin{array}{l}\text { Thematic panels' } \\
\text { feedback }\end{array}$ & $\begin{array}{l}\text { Project management and } \\
\text { monitoring, followed up by } \\
\text { review }\end{array}$ & $\begin{array}{l}\text { Resources needed for } \\
\text { completion of foresight } \\
\text { study versus resources } \\
\text { scheduled (financial } \\
\text { budget) }\end{array}$ \\
\hline \multirow{2}{*}{$\begin{array}{l}\text { Accomplishment } \\
\text { of the formally } \\
\text { set goal in terms } \\
\text { of specifying } \\
\text { research areas }\end{array}$} & $\begin{array}{l}\text { Personal and formal } \\
\text { information obtained from } \\
\text { client and stakeholders }\end{array}$ & \\
\hline & $\begin{array}{l}\text { Comparing with cost of } \\
\text { similar projects in other } \\
\text { countries }\end{array}$ & \\
\hline
\end{tabular}

urable over sector-specific policies. Foresight studies are often characterized as having little intrinsic value, with a small or absent involvement of policy decision makers, and a perception that the foresight study provides only informative frameworks.

Foresight has a lasting positive impact on the innovation performance of countries when it facilitates the cooperation of the initiators with major stakeholders in the early stages of the study. A foresight study often combines a top-down approach at the beginning and a bottom-up one at later stages. The necessary acceptance of the expected results is thus part of the objective from the beginning. 
Table 16.3 Impact of foresight studies

\begin{tabular}{|c|c|c|c|c|c|}
\hline & & \multicolumn{4}{|c|}{ Impact type and time horizon } \\
\hline & & \multicolumn{2}{|l|}{ Direct } & \multicolumn{2}{|l|}{ Indirect } \\
\hline & & Short-term & Long-term & Short-term & Long-term \\
\hline \multirow[t]{3}{*}{$\begin{array}{l}\text { Main } \\
\text { domains of } \\
\text { impact }\end{array}$} & Science & $\begin{array}{l}\text { Interaction/ } \\
\text { inspiration } \\
\text { with } \\
\text { non-science }\end{array}$ & $\begin{array}{l}\text { New/ } \\
\text { adapted } \\
\text { research } \\
\text { priorities/ } \\
\text { fields }\end{array}$ & $\begin{array}{l}\text { Horizon } \\
\text { expansion }\end{array}$ & $\begin{array}{l}\text { Industrial and } \\
\text { inter- } \\
\text { disciplinary } \\
\text { spillovers }\end{array}$ \\
\hline & $\begin{array}{l}\text { Economy } \\
\text { and } \\
\text { society }\end{array}$ & $\begin{array}{l}\text { Awareness } \\
\text { building }\end{array}$ & $\begin{array}{l}\text { Improved } \\
\text { techno- } \\
\text { logical } \\
\text { know-how }\end{array}$ & $\begin{array}{l}\text { Increased } \\
\text { productivity }\end{array}$ & $\begin{array}{l}\text { Targeted R\&D } \\
\text { investments, } \\
\text { improved } \\
\text { competi- } \\
\text { tiveness and } \\
\text { innovative- } \\
\text { ness of } \\
\text { countries/ } \\
\text { nations }\end{array}$ \\
\hline & Policy & $\begin{array}{l}\text { Application } \\
\text { thinking }\end{array}$ & $\begin{array}{l}\text { Priority } \\
\text { setting, NIS } \\
\text { shaping }\end{array}$ & $\begin{array}{l}\text { Increased } \\
\text { problem } \\
\text { awareness }\end{array}$ & $\begin{array}{l}\text { Increased } \\
\text { general } \\
\text { satisfaction }\end{array}$ \\
\hline
\end{tabular}

Foresight improves communication and cooperation between participants of different sectors and disciplines. Interdisciplinary thinking is strengthened and a common language is developed. Besides common indicative visions of the future, new targeted innovation policy measures can be developed from a solid base. Such harmonization of participants within NIS is essential for the exhaustion of the new (technological) potential and in particular for states with fragmented innovative systems. Foresight studies contribute, by the inclusion of the public, to the strengthening of the acceptance of the technology and innovation among stakeholders and society. However, national foresight studies are also a political process during which, perhaps, entrenched views influence the results (Cuhls 2003).

Foresight is to be understood as a continuous process from the initial goal definition to implementation. However, it is essential that implementation is considered in the early planning stage. Foresight studies are not finished when the results are presented; rather they begin, again and again, with an increasing impact over a long learning process. 


\section{HOW FORESIGHT CAN CONTRIBUTE TO STI INDICATORS}

One of the peculiar features of foresight is its focus on extracting and integrating tacit knowledge (Meissner 2013b). The many opportunities for the use of STI indicators to facilitate this process were discussed above. Foresight has a great potential to complement STI indicators. Below some of the most promising areas of such complementarity are discussed.

\section{Identification of Emerging Areas of Research}

Most foresight studies in the field of STI are aimed at identification of key research areas and key technologies, with the highest promise of economic and social return to be addressed by the national or regional governments. Since they are related to future issues, an opportunity is created to take a closer look at emerging areas of research, such as nano-, bio- and cognitive technologies. The new fields of S\&T identified through foresight can both contribute to existing statistical classifications and nomenclatures by introducing new research fields or innovative goods and services. On the other hand, there is room for new indicators to be measured in the framework of statistical surveys. For example, there are many new issues in the field of information and communication technologies that are poorly covered by statistics, while being among the key topics discussed within forward-looking activities, such as Web 2.0, cloud computing, social networks and semantic search.

Fast progress in the emerging S\&T areas requires new instruments for measuring them. The foresight community can be addressed in this respect as a source of new indicators that should be used in the planned surveys and a tool to elaborate a future time-line for introduction of those indicators into statistical practices.

In the OECD Blue Sky II Forum (OECD 2007), several challenges for STI statistics were discussed. One of them was a new context for STI indicators - globalization, fast changes in STI, and technological shifts towards emerging economies. Since foresight integrates judgements of a wide range of stakeholders, including researchers, business people and government officials, it makes it possible to identify promising areas of innovation activities and key factors that will reflect the future role of particular research areas so that the STI statistics can be better prepared to meet the future demands of policy makers. 


\section{Global Challenges}

A key issue for forward-looking activities is to address the global challenges: globalization, climate change, energy, an ageing population, scarcity of basic resources, migration, food and water security, health and well-being and sustainable development. ${ }^{3}$ In Boden et al. (2010) three major groups of global challenges are considered. They are the need to: change the current ways in which essential natural resources are used; anticipate and adapt to social changes; and foster more effective and transparent governance. STI, on the one hand, plays a crucial role in designing relevant responses to meet the challenges and, on the other hand, constitutes some of the particular challenges themselves. The convergence of conventional technologies and the emergence of new (multidisciplinary) fields of research create a potential for great impact on all dimensions of life. Foresight provides tools for the identification of early (weak) signals of changes to come, thus outlining a future policy agenda and introducing new indicators to measure the results of future policy making. Among the issues to be tackled by foresight and STI indicators are the impact of convergent technologies on various sectors of the economy and new modes of research (such as web-based labs distributed over different countries, open innovation, and research collaboration across countries and disciplines).

\section{Industry-Science Linkages and Multidisciplinarity of Research}

Measuring linkages between the science community and industry has been one of the most urgent issues for STI statistics (see, e.g., OECD 2007: 38). It covers such issues as cooperation, co-publication and co-patenting between research institutions and companies, university-industry relations and spin-off companies. Another dimension in this respect is increasing multidisciplinarity of research and innovation. Foresight, in its essence, is a participatory process that involves all types of stakeholders and thus creates new linkages in the 'triple helix'. On the other hand it can be used to identify new types of linkages and to assess key characteristics of emerging research networks (Nugroho and Saritas 2009).

Statistical time series are often used as a key source of information for economic models. At the same time the underlying assumptions do not necessarily reflect real processes and causal relationships between the indicators used in the model. The value of conventional models deteriorates with rapidly advancing technologies and increasingly complicated systems of policy tools. Foresight contributes to both deeper-expertbased analysis of trends and correlations within existing models and to the identification of new (not necessarily directly related to STI) drivers 
of changes and relationships between them to be included in the models. John Marburger notes that 'we need models that stimulate social behavior and that feeds into macroeconomic models ... that we can exercise to make intelligent guesses at what we might expect the future to bring and how we should prepare for it' (OECD 2010: 31).

Foresight provides a number of instruments allowing for the contribution of added value to existing models. Among other methods, there are scenario workshops where experts select the most important and most unpredictable variables to design relevant scenarios and indicators that can be used to show policy makers which scenario is taking place.

\section{OUTLOOK - HOW FORESIGHT AND STI INDICATORS WILL BE INTEGRATED IN THE FUTURE}

$\mathrm{R} \& \mathrm{D}$ is becoming a globally sourced commodity, especially by multinational companies. For these companies foresight is a useful tool to identify new areas of application and to get insights into expected national STI priority fields. Hence a major application for the results of foresight studies will be the influence of these results on R\&D policy priorities, which in turn will require statistical measurement in support of sound indicators.

$\mathrm{R} \& \mathrm{D}$ priority fields identified and assessed in such a way also deliver valuable information for governments but also for private investors, for example companies and financial investors, since the assessment of these fields and applications in turn allows to measure the value of $R \& D$ projects and portfolios. Eventually the combination of the calculated value of these $R \& D$ fields and applications allows the overall assessment of the innovation pipeline, especially of companies.

Moreover, foresight is a tool that has the potential to deliver results for the prospective development of the higher education sector, such as the design of future-oriented curricula of universities to meet prospective demand for skills. Foresight is likely to evolve as an instrument to identify the key skills/competences needed to work with emerging technologies and hence for revising existing nomenclatures for professions and programmes of professional education. In that respect, methodologies addressing weak signals and their implications for change will develop. In addition, foresight will go much beyond the established fields and horizons of investigation but will include policy fields complementary to STI policy. Hence foresight will be used as an instrument for the identification of future needs and policy issues and, as a consequence, will highlight the need for new indicators. In the short term the need for the substantial validation of trends 
identified and described with the help of foresight studies will be met. Such validation will eventually lead to building classifications and nomenclatures for emerging technology areas. The close interrelation of foresight, indicators and policy making requires building an integral system that will be able to identify future issues of concern, elaborate efficient policy tools (with a shared responsibility between different government agencies - a policy mix) and have a set of indicators able to measure progress and the effects. Eventually foresight mapping is likely to become one source for developing new STI indicators that are also well suited to correspond to the emergence of more sophisticated scenarios, for example indicators that reflect the shift to particular scenarios and can be used to identify and to describe key drivers (the most important and the most unclear).

The emergence of the foresight diamond (Figure 16.1) and its increased application also calls for more evidence-based methods, especially the integration of the qualitative and the quantitative. Such a new generation of indicators requires a move towards net-based indicators that are also capable of reflecting the increased use of web-based tools for the purpose of foresight. Such indicators are required to reflect new methods such as data mining and semantic search. In addition, the process perspective needs complementary indicators that describe the importance and functioning of networks within foresight.

\section{NOTES}

1. This chapter was prepared with the kind support of the National Research University, Higher School of Economics, Basic Research Fund.

2. For details, see NISTEP (2010) and Loveridge et al. (1995).

3. Global challenges have been extensively discussed during recent years by international organizations (see OECD 2010 and the Millennium projects - www.millennium.org).

\section{REFERENCES}

Battistella, C. and A.F. De Toni (2011), 'A methodology of technological foresight: a proposal and field study', Technological Forecasting and Social Change, 78, 1029-48.

Bezold, C. (2010), 'Lessons from using scenarios for strategic foresight', Technological Forecasting and Social Change, 77, 1513-18.

Bishop, P., A. Hines and T. Collins (2007), 'The current state of scenario development: an overview of techniques', Foresight, 9(1), 5-25.

Blind, K. (2004), The Economics of Standards: Theory, Evidence, Policy, Cheltenham, UK and Northampton, MA, USA: Edward Elgar.

Boden, M., C. Cagnin, V. Carabias, K. Haegeman and T. Konnola (2010), Facing the Future: Time for the EU to Meet Global Challenges, EUR 24364 EN, Luxembourg: Publication Office of the EU. 
Bradfield, R., G. Wright, G. Burt, G. Cairns and K. Van Der Heijden (2005), 'The origins and evolution of scenario techniques in long range business planning', Futures, 37(8), 795-812.

Cachia, R., R. Compañó and O. Da Costa (2007), 'Grasping the potential of online social networks for foresight', Technological Forecasting and Social Change, 74, 1179-203.

Cuhls, K. (2003), 'From forecasting to foresight processes - new participative foresight activities in Germany', Journal of Forecasting, 22, 93-111.

Gavigan, J., F. Scapolo, M. Keenan, I. Miles, F. Farhi, D. Lecoq, M. Capriati and T. Di Bartolomeo (2001), FOREN (Foresight for Regional Development Network): A Practical Guide to Regional Foresight, Brussels: European Commission Research Directorate General, STRATA Programme, http://foresight.jrc.ec.europa.eu/documents/ eur20128en.pdf.

Georghiou, L. and M. Keenan (2006), 'Evaluation of national foresight activities: assessing rationale, process and impact', Technological Forecasting and Social Change, 73, 761-77.

Georghiou, L., J.C. Harper, M. Keenan, I. Miles and R. Popper (eds) (2008), The Handbook of Technology Foresight: Concepts and Practice, Cheltenham, UK and Northampton, MA, USA: Edward Elgar.

Godwin, P. and G. Wright (2010), 'The limits of forecasting methods in anticipating rare events', Technological Forecasting and Social Change, 77(3), 355-68.

Grim, T. (2009), 'Foresight Maturity Model (FMM): achieving best practices in the foresight field', Journal of Futures Studies, 13(4), 69-80.

Haegeman, K., E. Marinelli, F. Scapolo, A. Ricci and A. Sokolov (2013), 'Quantitative and qualitative approaches in FTA: from combination to integration?', Technological Forecasting and Social Change, 80(3), 386-97.

Höjer, M. and L.G. Mattsson (2000), 'Determinism and backcasting in future studies', Futures, 32(7), 613-34.

Keenan, M. (2003), 'Identifying emerging generic technologies at the national level: the UK experience', Journal of Forecasting, 22, 129-60.

Keenan, M. and R. Popper (2007), RIF (Research Infrastructures Foresight). Practical Guide for Integrating Foresight in Research Infrastructures Policy Formulation, Brussels: European Commission.

Lempert, R.J., S.W. Popper and S.C. Bankes (2003), Shaping the Next One Hundred Years: New Methods for Quantitative Long-Term Policy Analysis, Santa Monica, CA: The RAND Pardee Center, http://www.rand.org/pubs/monograph_reports/2007/MR1626.pdf.

Loveridge, D., L. Georghiou and M. Nedeva (1995), United Kingdom Foresight Programme, Manchester UK: PREST, University of Manchester.

Malanowski, N. and A. Zweck (2007), 'Bridging the gap between foresight and market research: integrating methods to assess the economic potential of nanotechnology', Technological Forecasting and Social Change, 74, 1805-22.

Martin, B.R. (1995), 'Foresight in science and technology', Technology Analysis and Strategic Management, 7(2), 139-68.

Meissner, D. (2013a), 'Results and impact of national foresight-studies', in D. Meissner, L. Gokhberg and A. Sokolov (eds), Science, Technology and Innovation Policy for the Future: Potentials and Limits of Foresight Studies, Berlin: Springer, forthcoming.

Meissner, D. (2013b), 'Indicators for foresight studies', in D. Meissner, L. Gokhberg and A. Sokolov (eds) Science, Technology and Innovation Policy for the Future: Potentials and Limits of Foresight Studies, Berlin: Springer, forthcoming.

Meissner, D., M. Cervantes and V. Roud (2013), 'Innovation policy or policy for innovation?', in D. Meissner, L. Gokhberg and A. Sokolov (eds), Science, Technology and Innovation Policy for the Future: Potentials and Limits of Foresight Studies, Berlin: Springer, forthcoming.

Miles, I. (2002), Appraisal of Alternative Methods and Procedures for Producing Regional Foresight, Report, prepared by CRIC for the European Commission, DG Research, STRATA-ETAN Expert Group Action, Manchester, UK: CRIC.

Moed, H.F., W. Glänzel and U. Schmoch (eds) (2004), Handbook of Quantitative Science and Technology Research, Dordrecht, The Netherlands: Kluwer Academic Publishers. 
Molas-Gallart, J., R. Barrè, M. Zappacosta and J. Gavigan (eds) (2002), A TransNational Analysis of Results and Implications of Industrially-Oriented Technology Foresight Studies (France, Spain, Italy \& Portugal), JRC/IPTS-ESTO Study, Brussels: Joint Research Centre, http://bookshop.europa.eu/en/a-trans-national-analysis-of-resultsand-implications-of-industrially-oriented-technology-foresight-studies-pbLFNA20138/? CatalogCategoryID $=$ O1oKABstRQYAAAEj1JEY4e5L.

NISTEP (2010), The 9th Science and Technology Foresight, Contribution of Science and Technology to Future Society, NISTEP Report No. 145, Tokyo: NISTEP.

Nugroho, Y. and O. Saritas (2009), 'Incorporating network perspectives in foresight: a methodological proposal', Foresight, 11(6), 21-41.

OECD (2007), Science, Technology and Innovation Indicators in a Changing World. Responding to Policy Needs, Paris: OECD.

OECD (2010), The OECD Innovation Strategy. Getting a Head Start on Tomorrow, Paris: OECD.

Popper, R. (2008), 'How are foresight methods selected?', Foresight, 10(6), 62-89.

Popper, R. (2011), 'Wild cards and weak signals informing and shaping research and innovation policy', paper presented at the Fourth International Seville Conference on FutureOriented Technology Analysis (FTA): FTA and Grand Societal Challenges - Shaping and Driving Structural and Systemic Transformations, Seville, 12-13 May.

Rappert, B. (1999), 'Rationalising the future? Foresight in science and technology policy coordination', Futures, 31, 527-45.

Ringland, G. (1998), Scenario Planning: Managing for the Future, Chichester and New York: Wiley.

Santo, M., G. Coelho, D. dos Santos and L. Filh (2006), 'Text mining as a valuable tool in foresight exercises: a study on nanotechnology', Technological Forecasting and Socia Change, volume 73(8), 1013-27.

Saritas, O. and A. Oner (2004), 'Systemic analysis of UK foresight results - joint application of integrated management model and roadmapping', Technological Forecasting and Social Change, 71, 27-65.

Sokolov, A. (2013), 'Foresight in Russia: implications for policy making', in D. Meissner, L. Gokhberg and A. Sokolov (eds), Science, Technology and Innovation Policy for the Future: Potentials and Limits of Foresight Studies, Berlin: Springer, forthcoming.

TFAMWG (Technology Futures Analysis Methods Working Group) (2004), 'Technology futures analysis: toward integration of the field and new methods', Technological Forecasting and Social Change, 71, 287-303.

Tran, T. and T. Daim (2008), 'A taxonomic review of methods and tools applied in technology assessment', Technological Forecasting and Social Change, 75(9), 1396-405.

van der Steen, M., M. van Twist, M. van der Vlist and R. Demkes (2011), 'Integrating futures studies with organizational development: design options for the scenario project "RWS2020", Futures, 43, 337-47.

van Notten, P.W.F., J. Rotmans, M.B.A. van Asselt and D.S. Rothman (2003), 'An updated scenario typology', Futures, 35, 423-43.

Vishnevskiy K., O. Karasev, D. Meissner and E. Vetchinkina (2013), 'Integrated roadmaps for technology forecasting and application potential assessment - the case of applying nanotechnology to water treatment', in D. Meissner, L. Gokhberg and A. Sokolov (eds), Science, Technology and Innovation Policy for the Future: Potentials and Limits of Foresight Studies, Berlin: Springer, forthcoming.

Voros, J. (2006), 'Introducing a classification framework for prospective methods', Foresight, $8(2), 43-56$.

Wehnert, T. and W. Jörß (2009), 'Integration of qualitative and quantitative methodologies for European energy foresight', EFONET 2009. www.efonet.org. 